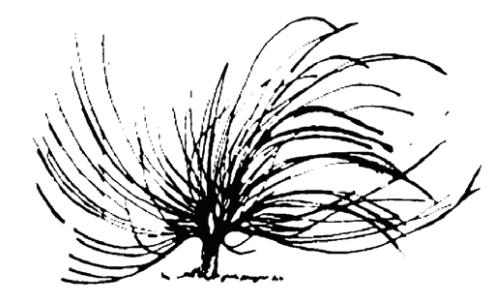

\title{
Algebraic Thinking: Conceptions of Elementary School Teachers
}

\author{
Ana Sofia Rodrigues Rézio ${ }^{1}$ \\ Instituto Superior de Ciências Educativas de Odivelas \\ Portugal \\ sofiarezio@hotmail.com
}

\begin{abstract}
Students' algebraic reasoning, at the beginning of their schooling years, includes the development and promotion of functional thinking and the understanding of mathematical properties, which can be stimulated by solving problems. In the latest Portuguese Program for Mathematics Elementary Education, we do not see the topic Algebra in the first year of school although some other topics include objectives of algebraic nature. This fact showed the importance of research about the introduction of concepts and development of algebraic skills by elementary school teachers. We investigated the concept of algebraic thinking and how it has been addressed, by interviewing 50 teachers from Portugal. The results showed that the respondents agree with algebraic experiences in the early years of school; however, the data
\end{abstract}

\section{(c) $($ i) $\Theta$}

Recibido: 8 mayo de 2013-Aprobado: 13 de abril de 2015

1 Ana Sofia Rézio is a researcher of the CeiED at the Education Institute of the Lusophone University of Humanities and Technologies, Portugal. She has published several papers in the area of Mathematics Education. She is a Maths teacher at school D.Pedro IV, Sintra. Master Degree in Mathematics (Numerical Analysis and Computational Mathematics), at the Faculty of Sciences, University of Lisbon (2007). Major Degree in Mathematics Education at the Lusophone University of Humanities and Technologies, Lisbon (2004). Major Degree in Mathematics (Numerical Analysis and Computational Mathematics), at the Technical Superior Institute, Technical University of Lisbon (1996). 
showed a considerable distance when compared to the concept of "algebraic reasoning" adopted by the current scientific community have of algebraic reasoning. With regard to activities that contribute to its promotion, problem solving was considered to play an important role in the development of algebraic skills as well as its representation and generalization.

Keywords: elementary school, algebraic reasoning, algebrization of arithmetics, functional thinking, generalization

\section{Resumen}

El pensamiento algebraico del estudiante, al inicio de su escolarización incluye el desarrollo y la promoción del pensamiento funcional y la comprensión de propiedades matemáticas, que puede ser estimulada mediante la resolución de problemas. En el último programa de Matemáticas de la Educación Básica Portuguesa, no se ve el tema de algebra, aunque hay objetivos de naturaleza algebraica en otros temas. Este hecho mostró la importancia de la investigación acerca de la introducción de los conceptos y el desarrollo de habilidades algebraicas mediante la enseñanza primaria. Investigamos el concepto de pensamiento algebraico y como éste se ha abordado, entrevistando a 50 maestros portugueses. Los resultados mostraron que los encuestados están de acuerdo con las experiencias algebraicas en los primeros años de escolaridad, sin embargo, los datos mostraron una distancia considerable debido al diseño que la actual comunidad científica tiene de pensamiento algebraico. Con respecto a las actividades que contribuyen a su promoción, la resolución de problemas se considera que tienen un papel importante en el desarrollo de habilidades algebraicas como su representación y generalización.

Palabras clave: razonamiento algebraico, escuela primaria, algebrización de aritmética, pensamiento funcional, generalización 


\section{Introduction}

There is no clear consensus about the definition of algebraic reasoning in early school years. However, investigators share the opinion that, at that stage, algebraic reasoning extends beyond Computational Arithmetics given to the underlying mathematics structure (Cai \& Moyer, 2008).

Research in an area that became known as Initial Algebra gained special prominence with the work of the Group for the Psychology of Mathematics Education [PME] in 2001. This is a group of researchers established in 1976 at the International Congress on Mathematics Education (ICME3) in Karlsruhe, Germany. The aims of the organization are: to promote international contacts and exchange of scientific information in the field of mathematical education, to promote and stimulate interdisciplinary research in the aforesaid area and to further develop a deeper and more correct understanding of the psychology and other aspects of teaching and learning mathematics and the implications thereof.

For one of its researchers, Kieran (2007), Algebra is much more than a body of knowledge and techniques: it is a way of thinking, and a child's success in Algebra depends at least on six types of mathematical reasoning skills: generalization, abstraction, analytical thinking, dynamic thinking, modeling and organization. In fact, algebraic thinking is a way of thinking a set of concepts and developing skills, allowing students to generalize, model and analyze mathematical situations (NCTM, 2008). In early Algebra, developing functional reasoning and understanding mathematical properties are underlined (Kieran, 2006); such skills can be stimulated by solving problems.

For Carraher et al. (2006), the approach to Algebra in early years of school should be guided by the perspective that generalization is the heart of algebraic reasoning; arithmetic operations can be viewed as functions, and algebraic notation can lend support to mathematical reasoning even among young students. These researchers argue that give functions greater prominence in the elementary mathematics curriculum helps to facilitate the integration of Algebra in the existing curriculum in more advanced stages.

We have already mentioned that algebraic reasoning can be seen as a process in which students generalize mathematical ideas departing from particular examples and express this generalization in a symbolic and appropriate way for their age. In this process, we should give 
attention not only to objects but also to the relationships between them and reasoning progressively in a general and abstract manner.

It is important that small children understand not only mathematical contents, but also that they get involved in the following procedures: looking for patterns, reasoning about data, solving problems and verbalizing their ideas and results (Baroody, 2002).

In summary, the concept of Algebra refers to the manipulation and formalization of mathematical concepts and structures mediated by explicit notational systems and guided by rules (Thomson and Smith III, n.d.). For this reason, the content of Algebra depends on ideas of consistency, representation, generalization and abstraction.

\section{When to introduce algebraic thinking}

The relevance of knowing if Algebra should be taught across the years of school has been debated since 1960. In fact, research on student's algebraic reasoning at an early age is relatively recent (Kieran, 2006). According to Kieran (2007), the advantage of incorporating a framework of algebraic reasoning in early years is that it fills a disconnection that has been observed for a long time between efforts to introduce early algebraic reasoning and the large body of Algebra research that has been dedicated to older students of ages 12 or 13 years.

According to Cai and Moyer (2008), if students and teachers routinely spent the first six years of school developing arithmetic and algebraic reasoning simultaneously with different emphasis depending on stages of learning, Arithmetic and Algebra would be seen as inextricably linked.

\section{How to introduce algebraic thinking}

Algebraic reasoning develops better from continuous exposure to patterns and relationships starting at Kindergarten (Steen, 1998). For Steen (1998), most Algebra is an extension of the Arithmetic universe to more abstract quantities represented by letters.

Concerning the evolution from arithmetic reasoning to algebraic reasoning, Vlassis and Demonty (2008) focused on the interpretation of the meaning of the equal sign, algebraic expressions and letters; thus, many students can be able to work in Algebra without simply retaining an arithmetic way of thinking. 
According to Ameron (2003), the rupture between Arithmetic and Algebra is related with the type of approach taken during problem solving since arithmetic problems can be solved directly through direct answers, while algebraic problems are necessarily translated into a formal language and representation and then solved. We would say that it is necessary to attenuate the difference between arithmetic and algebraic problems, solving these as arithmetic-algebraic problems; that is, numbers are not only understood as entities but also as relationships between those numbers and between numbers and operations. This perspective brings out the importance of the smooth transition from arithmetic to algebra teaching.

For Kieran (2004), students who operate on an arithmetic frame of reference tend not to see the relational aspects and operations' properties, focusing on calculus. Thus, for a successful transition from Arithmetic to Algebra, it is necessary that thought should not be limited to the calculation of a numerical answer but it has to be focused on relationships; also thought must focus on operations, as well as on their inverses, that is, on the idea of making and unmaking; moreover, students should focus on representation and not just on problem solving, giving attention to numbers and letters.

According to Blanton and Kaput (2003), it is important to create a culture of learning practices that promotes algebraic reasoning, which implies incorporating argumentation, conjectures and generalizations for students to consider purposeful arguments as a means for building reliable knowledge. In a study conducted by these researchers, students from $3 \mathrm{rd}$ and 5 th grades failed to discover and justify generalizations such as "when you add zero to a number you get the number you started with" (NCISLA,2000) or "when you subtract a number from itself you get zero" (NCISLA,2000). This finding indicates that even students that do not use algebraic notation in their answers can express general algebraic properties of the number system.

In an article from the National Center for Improving Student Learning and Achievement in Mathematics and Science [NCISLA] (2000), researchers Thomas Carpenter and Linda Levi published a study which showed that professional development of an innovative teacher and the reorientation of mathematics teaching paved the way for students in 1st and 2nd grades of school to begin to think algebraically. Research results also showed that these students learned to construct and justify generalizations about properties and a structure 
underlying Arithmetics, and even developed special skills of articulation and representation.

In order to illustrate what was said above, figure 1 shows a set of activities applied to students from 1st and 2nd grades, to guide them into expressing a generalization about what happens when zero is added to a number. Not only were these children able to articulate the generalization but they were also able to take the discussion to a higher level mathematically.

Figure 1. Set of activities that lead students to generalizations

NUMBER SENTENCES USED
to Generate Generalizations
Below are examples of number sentences that
teachers used to help students articulate gener-
alizations about zero and multiplication.
Examples: $78+0=78 ; 23+7=23^{*}$
"When you add zero to a number,
you get the number you started with."
Examples: $96-96=0 ; 74-\square=74$
"When you subtract a number from itself,
you get zero."
Examples: $96 \times 0=0 ; 43 \times 0=43$ "
"When you multiply a number times zero,
you get zero."

Source: NCISLA (2000) 
The study shows that even 1 st and 2 nd grade children are able to argue about mathematical concepts and operations in ways not generally expected from students at this age. These students were able to express generalizations and reason about them. As demonstrated by the contents in figure 1, the main characteristics of algebraic reasoning will be outlined according to the following topics.

\section{Focus of algebraic thinking}

Investigation in this domain revealed the existence of several focus of algebraic reasoning be it in terms of Arithmetics structure (NCISLA, 2000), the ability to formulate generalizations (Schliemann et al, 2012) or the approach of operations as functions (Carraher et al, 2006).

\section{Arithmetics algebrization}

The formalism of using letters as variables is not suitable for younger students; however, Kieran (2007) explained that students at elementary levels can be introduced to algebraic thinking through numerical expressions using numbers as almost-variables, through statements such as $87-39+39=87$, which is true whatever the number you add and subtract back. These activities, which use numbers as almost-variables, enable teachers to help students to build bridges between acquired knowledge and algebraic knowledge without using algebraic symbols. This is what is defined as generalized arithmetic.

\section{Generalization}

Algebraic notation seems to help children to jump from a computational reasoning to the formulation of generalizations and helps to explain about how two sets of values are interconnected (Schliemann et al, 2012). Also Curcio (1997) agrees with this view and goes even further, considering that generalization beyond a simple pattern recognition often involves concepts of multiplication and proportion.

\section{Operations as functions}

An activity guided by Carraher and Schliemann (2007) consisted of asking students to fill in gaps in a table with two columns, one about the number of crackers' boxes and the other with the price to pay. Most students in the class began to treat each column as if these were separate 
issues. They completed the first column counting one by one and the second counting 3 by 3 , as shown in Figure 2.

Figure 2. Activity that relates the number of crackers boxes with the total price to pay

\begin{tabular}{|c|c|}
\hline crackers boxes & price to pay \\
\hline & $3 €$ \\
\hline 2 & $6 €$ \\
\hline 3 & $12 €$ \\
\hline 5 & \\
\hline 6 & \\
\hline & $21 €$ \\
\hline 8 & \\
\hline 9 & \\
\hline 10 & $30 €$ \\
\hline
\end{tabular}

Source: Carraher e Schliemann (2007)

The approach of these children did not involve reasoning about the relationship between the price and the number of crackers boxes. After working relationships with children, a few weeks later, these students were already working with multiplication tables and studying multiplicative relationships. Nine-year-old children were able to look for patterns and functional relationships between pure numbers devoid of quantitative references. They did not need concrete materials to support their reasoning about numerical relationships and even managed to deal with the nature of algebraic notation.

Despite different foci on algebraic thinking, Thomson and Smith III (n.d.) share the same opinion: preparing students for Algebra involves the modification of the curricula which leads them to use symbolic notation, representation, communication and thinking extension.

\section{Solving problems}

According to Kieran (2007), most of the work should not be to introduce young students to conventional algebraic notation, but rather to base it on the use of language and other algebraic representations to express ideas through informal tables and graphs. Problem solving presents itself as an 
ideal to explore Mathematics in the way described above. Mestre and Oliveira (2011) conducted a study whose intention was to develop the competences of algebraic reasoning in 4th grade students by exploring calculation strategies of particular numerical expressions which contribute to the mobilization of generalization, thus starting a journey towards symbolization. Preliminary results indicated that students recognized numerical relationships, the operations properties involved in specific numeric expressions and were able to describe generalizations in natural language, though they were still at an early stage of a journey towards symbolic language. Basically, they recognized the structure of underlying strategies for calculations in each task and identified numerical relationships of half and double as well as the distributive property of multiplication over addition involved in numerical expressions presented. Such operation properties allow the students to justify strategies and represent them through schemes and arrow diagrams, thus bridging the concept of function effectively.

\section{Materials, methods and procedures}

A semi-structured interview was conducted, departing from previous theoretical contributions, in order to access how the interviewed teachers envisaged their students' algebraic thinking. The process would require straightforward questions.

We interviewed 50 teachers of elementary school, public and private, all from Sintra municipality, Lisbon district. Half of them had 10-19 years of experience. The anonymity of the interviews was guaranteed. Questions were topic-organized: the concept of Algebra, the age at which children starts thinking in algebraic terms, activities which allow for the development of the algebraic thinking, focus of this kind of thought, Algebra and Arithmetics alongside problem solving.

Concerning the results of the enquiry, the responses to each question were subcategorized a posteriori; the quantitative analysis results are showed in the tables that follow.

\section{Discussion}

Concerning the tables bellow, in cases of registration of constructed responses, percentages do not sum up to 100 because many of the teachers interviewed referenced more than one category. 
a) When asked about their concept of Algebra, teachers' responses revealed different characteristics. Some related it only with numbers, which has the highest response rate, others with numbers and operations, and others with numbers and relationships.

b) Later, teachers were asked about the age they considered adequate for children to start developing algebraic reasoning. Seventeen of these teachers believed 3/4-year olds are able to reason in algebraic terms though Kieran's studies conclude otherwise. One of the teachers explained that since Kindergarten, at the age of $4 / 5$ it is important to work out what lies behind the numbers, the concepts, the sets, the clusters, addition and subtraction, i.e., add or remove numbers informally. Nineteen teachers considered the development of algebraic reasoning during Kindergarten appropriate. Yet, ten teachers responded that this should only occur during Elementary School, thus corroborating Cai and Moyer (2008).

c) With respect to activities that allow developing algebraic thinking, teachers gave answers that we organized categorically, after noticing that these were related to numbers, operations and problem solving, as shown in Table 1.

Table 1. Activities that allow developing Algebraic Thinking' students

\begin{tabular}{|c|l|c|c|}
\hline $\begin{array}{c}\text { CATEGORIES } \\
\text { (ACTIVITY ITENS) }\end{array}$ & $\begin{array}{c}\text { Subcategories } \\
\text { (Abilities to develop) }\end{array}$ & AbsolutE value & Relative value \\
\hline $\begin{array}{c}\text { NUMBERS AND } \\
\text { OPERATIONS }\end{array}$ & Number sense & 19 & $38 \%$ \\
\cline { 2 - 4 } & Mental calculus & 10 & $20 \%$ \\
\cline { 2 - 4 } & Regularities & 7 & $14 \%$ \\
\hline \multirow{2}{*}{$\begin{array}{c}\text { PROBLEMS } \\
\text { SOLVING }\end{array}$} & Reasoning & 37 & $74 \%$ \\
\cline { 2 - 4 } & Representing & 35 & $70 \%$ \\
\cline { 2 - 4 } & Verbalizing reasoning & 24 & $48 \%$ \\
\cline { 2 - 4 } & Generalizing & 11 & $22 \%$ \\
\cline { 2 - 4 } & Equation solving & 2 & $4 \%$ \\
\hline
\end{tabular}

The more frequently reported examples have to do with forms of representation and reasoning in problem solving, followed by the verbalization of that reasoning. Such answers agree with Ameron's (2003) opinion according to which problems should be translated into a formal language and represented prior to their resolution. 
Then, to illustrate the reference to different forms of representation, one of the teachers stated that in a problem, students are given three sweatshirts and they have to do everything possible to combine sets with four pairs of pants; so they use a two way table. On the other hand, in order to visualize different combinations other students can make a tree diagram, which introduces a different strategy of representation.

Activities involving generalization were cited by 11 teachers. Attributing them their due importance, a teacher explained that there are things that students already generalize, for example, in a given square, joining a vertex to the opposite vertex, one always gets triangles. Also Blanton and Kaput (2003) stated the importance of raising and generalizing results to promote algebraic reasoning.

d) All teachers had the opinion that the Algebra should be introduced in parallel with the Arithmetic, so they were requested to indicate some difficulties witnessed during the passage from Arithmetic to Algebra. Seven teachers identified difficulties in their students, related exclusively to numbers, while thirteen named difficulties related exclusively with problem solving. The difficulty most often referred was to understand the statement of a problem. One of the teachers said he start working this issue in the 2nd year of Elementary, essentially but he thinks there must be at first, a linguistic understanding of the problem's statement or of the situation that is exposed to them. For him, the biggest difficulty is realize what is asked to them and then thinks of a strategy to get there, this is, ways of represent concepts. Kieran (2007) also had underlined the importance of students to focus on the representation and not just in the numerical resolution of a problem. One of the skills that has not proven to be easy to develop in their students, to some of the teachers interviewed, was the ability to abstraction. This is well illustrated by the explanation of a teacher. In his opinion during their childhood were not created enough situations so that they develop this kind of reasoning that can happen with toys, games, they were not encouraged to question, analyze, organize, sort, so when they get to school they are not able to think about things or formulate hypotheses, because it requires abstract thinking.

e) About what they considered to be the focus of algebraic reasoning: Arithmetic' structure, working operations as functions or promote 
generalization activities, and identifying two reasons for that choice, we can refer to Table 2 .

Table 2 . Focus of Algebraic Thinking

\begin{tabular}{|c|c|c|c|}
\hline $\begin{array}{c}\text { Categories } \\
\text { (focus of algebraic } \\
\text { thinking) }\end{array}$ & $\begin{array}{c}\text { SUBCATEGORIES } \\
\text { (REASONS OF CHOICE) } \\
\text { IT ALLOWS TO WORK } \\
\text { ABOUT ... } \\
\end{array}$ & $\begin{array}{c}\text { Absolut } \\
\text { value }\end{array}$ & $\begin{array}{l}\text { RELATIVE } \\
\text { VALUE }\end{array}$ \\
\hline \multirow{3}{*}{$\begin{array}{l}\text { ArithmEtics' } \\
\text { structure } \\
(\mathbf{N}=11)\end{array}$} & From concrete to abstract & 5 & $10 \%$ \\
\hline & $\begin{array}{l}\text { Resolution's strategies and } \\
\text { development's reasoning }\end{array}$ & 4 & $8 \%$ \\
\hline & $\begin{array}{l}\text { Others (numeric decomposition, } \\
\text { contextualization or importance } \\
\text { of exams) }\end{array}$ & 3 & $6 \%$ \\
\hline \multirow{7}{*}{$\begin{array}{l}\text { work operations as } \\
\text { functions } \\
(\mathrm{N}=\mathbf{2 5})\end{array}$} & $\begin{array}{l}\text { Resolution's strategies and } \\
\text { development's reasoning }\end{array}$ & 10 & $2 \%$ \\
\hline & Contextualization & 7 & $14 \%$ \\
\hline & Discover relationships & 5 & $10 \%$ \\
\hline & From concrete to abstract & 4 & $8 \%$ \\
\hline & Representations & 3 & $6 \%$ \\
\hline & $\begin{array}{l}\text { Application of properties and } \\
\text { concepts }\end{array}$ & 3 & $6 \%$ \\
\hline & $\begin{array}{l}\text { Others (reasoning's } \\
\text { verbalization, regularities, } \\
\text { importance of exams or data } \\
\text { importance) }\end{array}$ & 6 & $12 \%$ \\
\hline \multirow{5}{*}{$\begin{array}{l}\text { PROMOTE } \\
\text { GENERALIZATION } \\
\text { ACTIVITIES } \\
(\mathrm{N}=12)\end{array}$} & Regularities & 5 & $10 \%$ \\
\hline & $\begin{array}{l}\text { Application of properties and } \\
\text { concepts }\end{array}$ & 4 & $8 \%$ \\
\hline & $\begin{array}{l}\text { Resolution's strategies and } \\
\text { development's reasoning }\end{array}$ & 4 & $8 \%$ \\
\hline & Discover relationships & 3 & $6 \%$ \\
\hline & $\begin{array}{l}\text { Outros (From concrete to } \\
\text { abstract, de contextualization or } \\
\text { representations) }\end{array}$ & 7 & $14 \%$ \\
\hline
\end{tabular}

The focus on work Operations as Functions was what had more votes, having been chosen by $25 \%$ of teachers surveyed. Also for Carraher et al (2006) this was the focus of algebraic thinking, as mentioned previously. 
The most reported reason for this choice was related to the fact that it is considered that in this way you can work different resolution's strategies and thus develop reasoning.

f) Then, teachers were faced with the classic problem "Five friends will greet each other with a handshake. How many handshakes will be given at the end? How would you propose to your students this to be exploited?", since the resolution of problems, addressed from the point of view of algebraic thinking, encompasses the main characteristics of this kind of thinking, as it has already been explained.

The ordering of categories presented is justified with different phases of solving a problematic situation: concretization, forms of representation, discusses of strategies or results and generalization. With exception of this last step, the first three were reported by a large number of teachers, highlighting the discussion of strategies or results.

With great relief, the discussion of strategies was reported. One of the teachers explained that he and their students saw the different representations they made and each one explained it to their colleagues. Only four teachers emphasized the generalization, which indicates the low importance given to it. Blanton and Kaput (2003) expressed their concern about creating a culture of practices that foment generalization as a mean of developing algebraic thinking.

\section{Conclusions}

The concept of algebraic reasoning appeared unclear to the teachers interviewed if we compare it with to what scientific community presents. In what concerns to the age of its introduction, the answers given mainly for Preschool, does not coincide with the age appointed by that community. About how to introduce this kind of reasoning, most teachers responded through activities involving numbers and operations, although it is not clear the importance attached to the structure, this is, to the properties of operations.

The responses of teachers were quite consistent with the opinions of researchers, with regard to problem solving, considering this as an excellent mean to develop different algebraic representations, ability to generalize reasoning, underlying structures and recognize strategies of calculus. 


\section{References}

Ameron, A. (2003). Focusing on Informal Strategies When Linking Arithmetic To Early Algebra. Educational Studies in Mathematics, 54, 63-75.

Baroody, A. (2002). Incentivar a Aprendizagem Matemática das Crianças. In B. Spodek, Manual de Investigação em Educação de Infância (pp. 333-390). Lisboa: Fundação Calouste Gulbenkian.

Blanton, M., \& Kaput, J. (2003, Outubro). Developing Elementary Teachers - Algebra Eyes and Ears. Teaching Chlidren Mathematics, pp. 70-77.

Cai, J. \& Moyer, J. (2008). Developing Algebraic Thinking in Earlier Grades:Some Insights from International Comparative Studies. Reston: NCTM.

Carraher, D., \& Schliemann, A. (2007). Early Algebra and Algebraic Reasoning. In F. Lester, Second Hanbook of Research on Mathematics Teaching and Learning: A project of the National Council of Teachers of Mathematics (pp. 669-705). N.C: Information Age Publishing.

Carraher, D., Earnest, D., Schliemann, A., \& Brizuela, B. (2006). Arithmetic and Algebra. In Early Mathematics Education. Journal for Research in Mathematics Education, 37(2) 87-115.

Curcio, F. (1997). What does Algebric Thinking look like and sound like with Preprimary Children? Teaching Children Mathematics, pp. 296-300.

Kieran, C. (2004). Algebraic Thinking in the Early Grades: What Is It? The Mathematics Educator, 8(1), 139 - 151.

Kieran, C. (2006). Research on the Learning and Teaching of Algebra. A Broadening of Sources of Meaning. In A. Gutièrrez, \& P. Boero (Eds.), Handbook of Research on the Psyschology of Mathematic Education. Past, Present and Future. (pp. 11-49). Rotterdam: Sense Publishers.

Kieran, C. (2007). What do we know about the Teaching end Learning of Algebra in the Elementary Grades? Reston: NCTM.

National Center for Improving Student Learning and Achievement in Mathematics and Science [NCISLA] (2000). Building a Foudantion for Learning Algebra in the Elementary Grades, 1(2). Available In http://www.wcer.wisc.edu/ncisla 
National Council of Teachers of Mathematics [NCTM] (2008). Algebra: What, When, and for Whom. Available In http://www.nctm. org/uploadedFiles/About_NCTM/Position_Statements/Algebra\%20final\%2092908.pdf

Mestre, C. \& Oliveira, H. (2011). Generalizar Estratégias de Cálculo: Um Estudo sobre o Pensamento Relacional de Alunos do $4^{\circ}$ Ano de Escolaridade. XXII SIEM. Lisboa.

National Center for Improving Student Learning and Achievement in Mathematics and Science [NCISLA] (2000). Building a Foudantion for Learning Algebra in the Elementary Grades, 1(2). Available In http://www.wcer.wisc.edu/ncisla

Schliemann, A., Carraher, D., \& Brizuela, B. (2012). When Tables Become Function Tabels. Available In http://ase.tufts.edu/education/faculty/docs/schliemanntables.pdf

Steen, L. (1998). Available In http://www.stolaf.edu/people/steen/ Papers/algebra_mn.pdf

Thomson, P., \& Smith III, J. (n.d.) Quantitative Reasoning and the Development of Algebraic Reasoning. In J. C. Kaput, Employing Children's Natural Powers to Build Algebraic Reasoning in the Context of Elementary Mathematics. (in press).

Vlassis, J. \& Demonty, I. (2008). A Álgebra Ensinada por Situações Problemas. Lisboa: Instituto Piaget. 